Bol. Acad. peru. leng. 65. 2019 (191-200)

\title{
CRITICA A LA EDUCACIÓN ACTIVA Y DE LA PSICOLOGÍA EVOLUTIVA
}

\author{
Heinrich Helberg Chávez \\ UARM
}

Fecha de recepción:

$03 / 03 / 2019$

Fecha de aceptación:

$31 / 05 / 2019$

I. Antecedentes políticos de la necesidad de una crítica de la psicología de Jean Piaget

Cuando el Dr. Juan Abugattas terminó su periodo como viceministro de Educación y yo, que era su director de Educación Rural y de Educación Bilingüe Intercultural, llegamos a la conclusión de que el «Nuevo Enfoque Pedagógico» que se sustentaba en la pedagogía activa que se derivaba de los estudios de Jean Piaget estaba en serios problemas, no solo en el Perú, sino en todo el mundo, y que la pedagogía activa no conseguía los resultados académicos esperados, aunque en el papel convencía frente a otras opciones más autoritarias.

Para entonces, culminadas las grandes capacitaciones en la pedagogía activa, era obvio que en el Perú se daba una resistencia cultural

https://doi.org/10.46744/bapl.201901.010 
contra el rol de facilitador que se le asignaba al docente en dicho modelo, que no era aceptable para las culturas originarias del Perú, especialmente para los pueblos andinos. Y que la supuesta «feliz coincidencia» entre esa «pedagogía activa» con las culturas pedagógicas de los pueblos amazónicos que no eran autoritarios no era tal, ni en los objetivos ni en las estrategias pedagógicas. Por eso el Dr. Abugattas convocó a una gran reunión de expertos que debían formular una nueva propuesta pedagógica, pero los expertos no pudieron generar nada nuevo, y más bien reafirmaron lo que se venía haciendo, como única opción. Faltó valor para apostar por los mismos fines y estrategias pedagógicas de los pueblos del Perú, que sería el sustento necesario e imprescindible del sistema educativo peruano: partir de lo que tenemos, en vez de optar por modelos extranjerizantes que siempre tendrán dificultades de aplicación porque entran en contradicción con las prácticas ya establecidas.

Otro etnocentrismo de la pedagogía activa es que cuando se apoya al niño a que construya su propio conocimiento, se lo hace con la lógica de las ciencias occidentales, identificando objetos, clasificando, ubicando, numerando y construyendo conceptos abstractos. Luego se formulan hipótesis, se comprueban, etc., sin caer en cuenta en que los conocimientos cotidianos del niño siguen otra lógica: que él está haciéndose de su universo semántico, aprendiendo los usos y las razones con que se juzga qué es qué en el lenguaje cotidiano, y que eso nada tiene que ver con un conocimiento objetivo del mundo ni con las ciencias como las conoce la modernidad ni con la visión científica del mundo. El niño se está introduciendo al discurso cotidiano, que es algo muy distinto que construir conocimiento objetivo.

Lo mismo sucede con los conocimientos culturales, que desde temprana edad inician a los niños en actividades productivas (que no es hacerlos trabajar) y que practican en sus casas y en sus salidas al campo. Aprenden, por ejemplo, a detectar peligros y a protegerse, a saber los usos de los recursos que poseen, dónde encontrarlos, y aprenden a conocer las relaciones entre las especies y los sistemas ecológicos. Saben quién se come a quién, por ejemplo, o cómo son las crías y cómo los animales adultos o cuáles son hembras y cuáles machos y sus costumbres. 
Conocen sus guaridas, por dónde andan y cómo se comunican. Saben que sus padres pueden imitar las voces de los animales y cuando responden aprenden a ubicarlos.

Estos conocimientos son seguro tan válidos como los conocimientos objetivos de las ciencias, pero siguen otros propósitos y otras reglas. No son conocimientos teóricos. La otra conclusión a la que se llegó como resultado de su periodo como viceministro fue que los currículos nacionales no se dejan diversificar y nunca se van a dejar diversificar porque hay un cambio de lógica de aprendizajes. Lo que los pueblos del Perú y sus líderes como Anderson Yumbato del pueblo kandoshi demandan es que se les enseñe con su lógica de conocimiento. La consecuencia es que se debe contar con un currículo intercultural de base. Conclusión a la que llegamos Luis Enrique López y yo conjuntamente. Esto significa no poner ningún sistema de conocimiento ni contenido como supuesto, sino definir las competencias y habilidades como saber gestionar la situación de salud familiar, digamos, al final de la educación básica, sin referirse a ningún tipo de medicina ni conocimiento en particular. Eso lo tiene que proporcionar la aplicación del currículo.

El tener un currículo intercultural es también lo que manda la ley general de educación vigente cuando se pone a la Educación Intercultural Bilingüe como un componente de la educación para todos los peruanos y no solo como un privilegio de los pueblos originarios. Se considera un privilegio y no una concesión, puesto que lo intercultural es por definición más universal que lo culturalmente específico, aunque se trate de la «aldea global»: sigue siendo una posición social específica y limitada.

Usar el modelo del multiculturalismo, de una vía principal y otras aportantes, no es lo que se entiende por intercultural, pero es lo que realmente se practica o propone como tal, lo que desfigura o reduce el concepto. Para ser intercultural, habría que negociar y dialogar entre las partes, permitir que dos o más sistemas de conocimiento contribuyan a la generación del mismo, tratando de que ese intercambio sea equitativo y que se subsanen las carencias de información sobre las reglas de las culturas para que haya una comprensión mutua, y que la vía para 
aprender del otro esté abierta y que juntos se creen nuevos sentidos y nuevos conocimientos. Sin productividad no hay interculturalidad, ya que se quiere que los pueblos generen nueva propiedad intelectual que puedan usar en sus proyectos de vida de pueblo. Esos son los criterios (indicadores) con los que se mide la interculturalidad, y habría que tomarlos en cuenta en los procesos educativos y de consulta. No basta con la intercomprensión. Esa propuesta se queda corta porque una interculturalidad crítica es consciente de la necesidad de salir de la subordinación cognitiva, social y económica.

Hay importantes razones para que la educación intercultural bilingüe sea para todos, para que los peruanos se conozcan y se gobiernen sobre la base de la intercomprensión, y también para el mismo avance de las ciencias, ya que la verdad no se deja establecer solo contrastando el modelo con la realidad, sino contrastando las visiones de los temas que tienen las distintas culturas entre ellas y que anteceden a los modelos o teorías. Por eso es que el futuro pertenece a las ciencias interculturales: simplemente refutarán las ingenuidades, cientificismos y compromisos sociales y económicos de las ciencias monoculturales.

La historia que sigue es conocida: se declaró por entonces a la educación en estado de emergencia y se redujeron los contenidos a los que eran instrumentales para el aprendizaje de otros contenidos, comunicación y matemáticas. Pero eso tampoco tuvo resultados medibles y los avances que se obtienen hasta la fecha son modestos. Para conseguir resultados más contundentes, como un $70 \%$ de niños con capacidad lectora adquirida en el primer año de enseñanza de lectura, habrá que hacer una autocrítica más decidida y sacar conclusiones de los hallazgos que ya se disponen.

Y habrá que reconocer que en las culturas pedagógicas de los pueblos están las opciones culturales. Los pueblos que constituyen la nación son en realidad la sustancia de la nación y solo a través del diálogo y la negociación con ellos pueden, democráticamente, introducirse nuevos horizontes de vida en la educación, sin forzamientos y sin querer aventajar al otro, porque esas son movidas ilícitas. Hay que superar la 
dependencia de modelos extranjerizantes, como una debilidad política, porque siempre hay que partir de la realidad propia. La otra opción es reproducir siempre el mismo esquema de intervención que quiere imponer modelos de éxito importado, pero que repiten sistemáticamente el mismo autoengaño y terminan estrellándose contra la realidad.

Uno de los problemas que se afronta es que no se ha criticado a fondo el modelo de la pedagogía activa y no se ha reconocido que el objetivo de tal pedagogía, desarrollar el pensamiento abstracto y las operaciones lógicas formales, no se sustenta porque, al no tener en cuenta Piaget los conocimientos sobre cosas y personas individuales (lo que en filosofía se llama "particulares») y no haber reconocido las formas prácticas de expresar generalizaciones, desconoce la lógica del aprendizaje más usada por los niños, que es la de la adquisición práctica (sin fórmulas ni generalizaciones explícitas) y que está firmemente anclada en el lenguaje cotidiano de todos los humanos.

Si al estudiante se le orienta a dedicarse solo a las ciencias, que - como se definen a sí mismas - se dedican exclusivamente a los conocimientos generales, se deja muchos usos y costumbres sin explicación y a las ciencias sin aplicación, puesto que las aplicaciones son siempre concretas y requieren de la racionalidad práctica. Esto significa que en la formación falta una última etapa en la que el joven aprenda a superar el conocimiento abstracto y general, tome en cuenta los contextos sociales, aterrice y tome consciencia social y ética de sus propuestas, sepa usar tanto generalizaciones prácticas como abstractas y sepa balancearlas con los conocimientos particulares para poder usar el conocimiento general.

Esto es lo tiene que hacer, por ejemplo, un médico cada vez que debe curar a una persona, la cual es un particular, con un metabolismo propio y distinto del de otras personas, en el que las mismas causas pueden tener efectos distintos. Mientras que en su estudio solo se ocuparon de las causas, los principios activos. Sobre este cambio de lógica nadie reflexiona ni tampoco se enseña; su procedimiento tiene implicancias éticas y por eso el conocimiento tiene una dimensión ética. 


\section{Crítica a J. Piaget y a la pedagogía enraizada en su psicología}

1. Piaget es etnocéntrico cuando pone la visión del mundo científico como objetivo de la educación a escala mundial. En su lugar, debería haber puesto el sentido común o la visión cotidiana de la vida, que sí son por definición universales. La visión del mundo científica no lo es ni nunca lo va a ser.

2. Esto se debe a que la psicología experimental carece de una visión de la arquitectura lógica de una cultura y que, si bien maneja la discusión filosófica (habla del juicio ético al modo kantiano), no debe haber conocido la discusión entre Reid y Kant sobre el sentido común vs. los conocimientos a priori ni tampoco la discusión de Moore y Wittgenstein sobre los supuestos prácticos y los marcos de referencia de la comunicación humana, que se publicaron mucho más tarde.

3. Piaget mide las etapas del desarrollo del niño con indicadores tomados de la visión científica del mundo, pero esa información no es un producto del conocimiento del niño, sino de toda la cultura que este recibe y que es imposible que genere por sí mismo. Los conocimientos sobre las constantes de la naturaleza, como la «permanencia» de los objetos naturales cuya existencia no depende de los sentidos, son producto de la acumulación generacional de conocimiento; no se podrían alcanzar en una vida, como no se puede esperar que un niño entienda por sí solo las fases de la luna o la rotación de la tierra.

4. En la arquitectura lógica de una cultura, las visiones de la vida no se enseñan, sino que se deducen del todo, de ejemplos, y funcionan como supuestos o marcos de referencia. Es característico de esta visión cotidiana de la vida, que es el sedimento de muchas experiencias y las coincidencias se producen sobre juicios prácticos como que si suelto una piedra que tengo en la mano, se cae, y no acerca de las explicaciones teóricas de tal suceso, que de hecho son controvertidas.

5. En consecuencia, los avances del niño habría que medirlos por los conocimientos que este adquiere por sus propios medios. Conocimientos 
como descubrir regularidades y proponer nuevas reglas, aprender a cambiar de roles o saber fantasear con comportamientos antifácticos deliberados que son parte de un juego, como cocinar sin ingredientes ni fuego o hablarle a la muñeca.

6. Piaget investiga el juicio ético del niño, es decir, las generalizaciones explícitas y argumentos que usa, y con eso se equivoca de lógica porque el niño aprende básicamente de forma práctica, interactuando, encontrando límites a sus impulsos inmediatos, imitando, o con ejemplos, muestras y modelos; no con reglas explícitas. Para cuando el niño puede juzgar el comportamiento ético de sus padres, ya pasó tiempo desde que adquirió una moral práctica de lo que puede y no hacer, como morder cuando lacta, y de eso Piaget no se percata porque desconoce la lógica del conocimiento práctico.

7. La etapa del desarrollo sensoriomotor que Piaget señala es, a su vez, la etapa de la inserción en el lenguaje, en la que el niño genera unidades de sentido en interacción con la madre, y esas unidades de sentido son intelectuales (reconoce a la madre), emocionales (se asusta) e interactivas (logra que lo limpien, que mitiguen el dolor). Así construye su propio universo de sentido, que desde un inicio es complejo y diverso, pero no es un conocimiento del mundo (como lo es la ciencia) como asume Piaget, sino que se trata de la construcción de relaciones sociales comunicativas, de una adecuación a prácticas regulares consensuadas.

8. Lo que el niño adquiere es la lógica del lenguaje cotidiano, que le permite seguir aprendiendo y le permite distinguir personas, acciones y cosas, y ese es su universo de sentido, pero eso no es un conocimiento más profundo de las cosas que le permite, por ejemplo, entender cómo funcionan o cómo se producen.

9. El lenguaje nos da el concepto, pero no el conocimiento. Eso requiere de otros procesos que pueden seguir la lógica de la adquisición de conocimiento práctico o la del teórico-contemplativo. Por eso es que la adquisición de la visión científica del mundo no viene al caso cuando se trata del proceso de socialización porque, como vimos anteriormente, el proceso 
https://doi.org/10.46744/bapl.201901.010

de socialización nos introduce en el mundo de los sentidos del lenguaje, sobre la base de reglas de uso que son reglas sociales, no producto de métodos para alcanzar conocimientos objetivos.

10. Llama la atención que los errores de Piaget no son errores comunes. No es que haya aplicado mal el método científico: todo lo contrario, es un ejemplo de trabajo científico riguroso, pero con errores de visión que provienen de la misma cultura en que se lleva a cabo la investigación. Si toda la comunidad científica comparte un prejuicio en una época, es difícil escapar de este, a menos que se provenga de otro contexto cultural o se trabaje con una visión distinta, y por eso es que el contraste cultural es un paso necesario para ser objetivos. Es algo que no se ha visto explícitamente en el método científico.

11. El método científico no evita ni previene los errores de visión, que son etnocentrismos que se meten en la concepción del tema que va a estudiar el investigador, y es así como el error de poner la visión científica en lugar de la visión cotidiana tiene consecuencias desastrosas porque invalida la categorización de las etapas de desarrollo del niño y el objetivo: ya no es el adquirir el conocimiento abstracto y el dominio sobre las operaciones lógicas formales, sino el saber aplicar las generalizaciones (prácticas y teóricas) a casos concretos que requieren de conocimientos sobre particulares.

12. El desconocimiento de la lógica práctica despista totalmente la investigación y la confusión entre el conocimiento del mundo y los conocimientos gramaticales es la expresión del desconocimiento total de la arquitectura interna de una cultura. 
https://doi.org/10.46744/bapl.201901.010

\section{BIBLIOGRAFÍA}

ARISTÓTELES. (1978). Metafísica. Traducción directa del griego, Introducción, Exposiciones Sistemáticas e Índices de Hernán Zucchi. Buenos Aires: Editorial Sudamericana.

FEYERABEND, P. $\left(1975^{1}, 1986\right)$. Tratado contra el método. Esquema de una teoría anarquista del conocimiento. Traducción de Diego Riba. Editorial Tecnos. Título original: Against Method. Londres: NLB.

HELBERG CHÁvEZ, H. (2008). Epistemología de la interculturalidad latinoamericana. Lima, UNICEF: El Vuelo de la luciérnaga, N. ${ }^{\circ} 1$.

. (2012). Aufgeklärte Praxis- Philosophie für das 21. Jahrhundert [La praxis lúcida - Filosofía para el Siglo XXI]. Concordia: Revista Internacional de Filosofía, 62. Alemania: Universidad de Aachen.

. (2014). Interkulturelle Epistemologie (Epistemología Intercultural). Concordia: Revista Internacional de Filosofía, 64. Alemania: Universidad de Aachen.

. (2015). La gestión del conocimiento, los pueblos indígenas y el poder. Desde el Sur, 6(2), 11-23.

. (2017). Las carreras interculturales en el centro de la discusión política y académica.

. (2017). Conocimiento intercultural. Indicaciones metodológicas. Lima: Sur, Escuela Superior de Gestión S.A.C.

- (2018). La libertad creativa como principio social. AMAZONÍA, Año 5, 13. 
https://doi.org/10.46744/bapl.201901.010

INTERCULTURALIDAD. (2000, 2001). Creación de un concepto y desarrollo de una actitud. Compilación y edición de María Heise. Lima: FORTE-PE.

WITTGENSTEIN, L. (1953, 2001). Philosophische Untersuchungen. Kritisch-genetische Edition. Herausgegeben von Joachim Schulte in Zusammenarbeit mit Heikki Nyman, Eike von Savigny und Georg Henrik von Wright. Frankfurt am Main: Suhrkamp Verlag.

. (1970). Über Gewißheit. Editado por G.E.M. Anscombe y G. H. von Wright. Frankfurt am Main: Suhrkamp Verlag.

. (1988). Investigaciones filosóficas. Traducción castellana de Alfonso García Suárez y Ulises Moulines. Barcelona: Editorial Grijalbo. 